\title{
Quality Bus Corridors in Dublin
}

Margaret O'Mahony

Department of Civil, Structural \& Environmental Engineering

Trinity College Dublin

Dublin 2

Ireland

Tel: +35316082084

Fax: + 35316773072

Email: margaret.omahony@tcd.ie

Word count: 6266 


\begin{abstract}
The perception of bus transport in Dublin has been and still is perceived to be a poor alternative to the car. It is generally seen as the 'poor person's' mode of transport with many people upgrading to car as soon as they can afford to do so. The result has seen a significant increase in traffic congestion fuelled by the recent period of economic growth during which car ownership levels have risen from 238 per 1000 in 1991 to 350 per 1000 in 1999. One of the main difficulties facing the state-owned bus company is that bus competes with car for limited road space.

In 1995, the Dublin Transportation Initiative proposed a new public transport strategy incorporating Light Rail Transit and what they described as Quality Bus Corridors (QBCs). To date nine out of eleven QBCs have been implemented. The characteristics of a QBC include a dedicated lane between 0700 - 1900 in most cases although some 24 hour bus corridors also exist. Although there is no physical separation between the bus lane and other lanes, enforcement by the police is strict and there is a relatively low level of non-compliance.

The paper describes the QBC concept in more detail and discusses the impacts since introduction in Dublin, examining in particular travel times, passenger numbers and reliability of service frequency. Future plans for bus transport in Dublin are mentioned, highlighting the significant contribution buses will be expected to make in solving Dublin's transport problems.
\end{abstract}




\section{INTRODUCTION}

Dublin is the capital city of Ireland and is situated on the eastern side of the island, the side closest to the UK. The Greater Dublin Area (GDA) stretches roughly to the boundaries of the maximum commuting distance from the city centre and has a population of 1.4 million. Its population is expected to rise to 1.65 million in 2011 . The population of the metropolitan area is expected to rise to 1.25 million, an increase of $12.5 \%$ whereas the population of the hinterland may rise to 402,000 , an increase of $36 \%$ (1). The number of households in the metropolitan area was 342,800 in 1991 and 392,685 in 1999. The number of people in the 15 - 65 age group was 740,900 in 1991 and 779,422 in 1999 . Unemployment levels today are at $3.1 \%$ compared with $15.7 \%$ in 1991.

The high rate of economic growth has resulted in a large increase in the demand for travel. Peak hour trips between 1991 and 1997 grew by $45 \%$ or 78,000, 71,000 of which are due to private car commuting. The average journey time increased from 31 minutes to 43 minutes over the same period with $72 \%$ of peak hour trips being accounted for by the private car. The forecast for 2016 is that there will be a 95\% increase in the total peak hour trips over and above that predicted for 2016 in 1997, while the off peak demand for trips in 2016 will also exceed the peak period demand in 1997 (2).

Road based transportation plans for the city were common in the 1980s. This was a period of recession during which there was significant lack of investment in public transport for many years. The Dublin Transportation Initiative (DTI) in 1995 (3) recommended a future strategy for Dublin with a high priority on public transport solutions with less emphasis on new roads. The public transport solutions proposed encompassed improved sub-urban rail (heavy rail), three Light Rail Transit (LRT) routes and eleven QBCs. The choice of LRT for three routes was based on the fact that the routes exhibited high traffic flows. However, strategic and political issues also played a role in the decision. An existing right of way which was maintained after an old rail line went out of service may also have been influential in deciding where one of the LRT routes would go. The second route goes to one of the most rapidly growing towns in the south-west of the city and the third goes to the airport. Two of the LRT lines are currently under construction - one to the south-west of the city and one to the south (on existing rail right-of-way). In addition to the new services, better integration between the modes is proposed along with significant traffic demand management measures such as increased pedestrianisation within the Central Business District (CBD), environmental traffic cells (sensitive areas - e.g. residential where through traffic is curtailed by blocked accesses or the provision of ramps) to curtail traffic through residential and other sensitive areas and increased parking charges.

Due to the problems of inaccuracy in prediction of transport demand associated with increased levels of economic activity and the relatively slow implementation of the plan, the Dublin Transportation Office (DTO) Short Term Action Plan (4) identified a deficit in terms of the original plan and its ability to match demand. Some of the deficit is due to the fact that LRT has not yet been introduced (15,000 person trips per peak hour) and that there is an increasing demand for car transport above predicted (49,000 person trips per peak hour). 
In economic terms, the costs of improvements included in The Irish National Development Plan (NDP) (5) includes a 2.67 billion Euro (\$2.67 billion) investment in public transport and of this 1.65 billion Euro (\$1.44 billion) will be spent in the GDA. This will include significant investment in suburban rail, bus and LUAS (name for new Light Rail Transit). The bus investment programme includes extensive fleet replacement at a cost of 73 million Euro (\$63.9 million) for 245 new buses during the period 2000 2006.

\section{BUS AS A TRANSPORT MODE}

Dublin in its transportation strategies has used a combination of modes as a means of providing transport solutions. Each mode has its advantages and disadvantages but in terms of public transport options, buses have an advantage over track-based systems in that they can be implemented more quickly and are perhaps more flexible in matching changing demands. On the other hand from the viewpoint of the passengers, bus speed is lower than rail based options and typically traffic congestion impacts on bus more significantly than on track based options. Capital investment is lower for bus options per unit of service and the lead-time for new service introduction is much less.

Large buses (80-100 passengers) are the most efficient means of moving people at flows between 400 - 2500 per hour per direction. If buses are allocated their own road space the allocation is justified at passenger flows over 2000 per hour (6). Flows below 200 passengers per hour do not justify large buses and mini and midi buses are normally used. Dublin uses a large proportion of double decker buses due to relatively long journey times and the requirement for a higher ratio of seat/stand in such situations. For routes where there is high turnover of passengers, double deckers are not as appropriate given the additional time taken for passengers to move between floors. Single deckers are more appropriate in these cases.

Some measures have been taken to reduce the dwell time at stops in Dublin including the introduction of several journey tickets which are inserted into an automatic checking machine while boarding. A 'no change' policy has also been introduced i.e. individuals who choose to buy their ticket on the bus must have the exact change for the ticket or if they pay more than what the ticket costs they have to reclaim the excess from the bus company at a later date. Typically many excess claims are not made and some charities have taken to collecting the tickets and processing the excess claims for charitable purposes.

\section{THE QUALITY BUS CORRIDOR (QBC) CONCEPT}

The QBC concept was devised during the DTI when it became clear that bus would be required to form a major part of the future strategy for Dublin. Bus had not worked very well previously in Dublin so additional measures were needed to ensure that the QBC could deliver in terms of offering a level of service that would be attractive to transport users. The QBCs, including those currently in operation and those due for implementation in the future, are presented in Figure 1. Those in operation include one to the north-east of the city - the Malahide QBC, one to the south - the Stillorgan QBC, 
two to the west - the Lucan and Blanchardstown QBC and one to the north - the Finglas QBC.

The main characteristics of a QBC are as follows:

- Allocated road space (taxis can use the same road space)

- Higher service frequency

- Shorter journey times

- Improved passenger facilities (e.g. shelters) although further improvement would be desirable

- Bus priority

These factors are important elements when defining transit/bus performance measures , quality of service, transit service measure and levels of service as categorised in the Transit Capacity and Quality of Service Manual (7)

The allocated road space for the QBCs is the lane nearest the kerb. Design standards are in accordance with current regulations. All QBC schemes are designed by engineering consultants and a safety audit is conducted at each stage of the process. Buses share this lane with taxis (taxis are considered to be public transport) and with cyclists. To provide this dedicated space, in many streets one lane was taken from general traffic use which in most cases meant halving the road space for car traffic. Excessive congestion levels have been noticeable just after the QBCs are introduced but the tendency is for this to reduce as car users either transfer to the bus or find an alternative route.

When a new QBC is introduced, the police force dedicate a significantly increased number of police to monitor the route for about six weeks after introduction after which spot checks are done by police motorcylists who receive specific training. If a car driver is caught in a bus lane a fine is issued. Other methods used for enforcement include city area wheel clamping and car removal if a car is found to be parked in a bus lane. (Parking infringements are dealt with severely in Dublin by means of a clamping and tow-away scheme where a significant fine is issued before the clamp is removed or vehicle recovery from a pound).

The city authority (Dublin Corporation) also monitors bus lanes using their Closed Circuit Television (CCTV) system. A good relationship exists between this authority and the police force so that the police can be called in very quickly to deal with an incident which is causing an obstruction. All methods of enforcement have contributed to ensuring that car drivers comply for the most part e.g. queuing to merge into the one lane provided for cars in advance of the start of the QBC is a common phenomenon. In general, bus drivers appear to be pleased with the level of enforcement although observation has shown that few journeys are not affected in some way by traffic or parking violations (6).

A higher service frequency is another characteristic of the QBCs. One of the complaints levelled at the bus company (Bus Atha Cliath - BAC) in the past is that in the peak hour buses reached capacity and could not accommodate all potential passengers. In implementing the QBCs this has been addressed by increasing the frequency in peak 
hours to 3 - 4 minutes so that if buses are full and pass a stop with waiting passengers, those people only have to wait a few minutes before another bus arrives.

One of the QBCs in particular caught the attention of the media. The reason for the significant interest was that the QBC - the Stillorgan QBC - served the wealthiest suburb in Dublin. There was an interest in how the authorities would stand up to the complaints of the residents given that at one bottleneck point on the route the road space allocated to car traffic was one lane compared with two in the past. Introduction of the QBC received strong support from Government. The service currently operates at Level of Service (LOS) A as defined in the TCQSM (7) compared with LOS C/D before the QBC was introduced. Current headways can be as low as 3 minutes and headways are only marginally greater than 10 minutes a few times a day. For almost all of the day $(7.00-23.30)$ the headways are $5-10$ minutes. After the initial excessive congestion levels, ridership on the buses increased, the details of which will be presented later. However, a comment made by one observer summed up the success of the QBC - 'there are now more suits on the buses'.

Journey times by bus have been reduced significantly - the QBC is competing very well with the journey times on a parallel suburban rail route. Journey times by car have increased which is understandable given the reduced road space. Passenger facilities have been improved although there is further room for improvement. Although timetables are available at the stops, no real-time information is provided at present although this issue has a high priority and may well receive attention in the near future.

A longer-term aim is for the QBC to have priority at signalled intersections. Although this was mooted quite strongly in the past, the authorities have grown relatively quiet on this issue recently. Some priority is currently given in the cases where a bus in the bus lane needs to cross into the general traffic stream e.g. to make a right turning movement shortly afterwards. In those cases, the bus is given a green light 4 seconds in advance of the cars so that it can enter the lane in advance of the car traffic.

\section{GENERAL OVERVIEW OF EXISTING QBCs}

- The QBCs are in effect traffic lanes with some traffic management measures

- More priority could improve the QBC service further

- Some bus lanes are discontinuous - some of Dublin's streets are narrow and it is not possible to physically divide up the road space to give two lanes - one for bus and one for general traffic

- Queuing for buses on city streets is a problem where most of the pathway is taken up with waiting passengers.

- Some of the major termini coincide with some of the most notoriously congested spots in the city. This means that buses have difficulty pulling out into the traffic stream. A more strategic design of where bus stops should be sited would benefit the city.

- No real-time passenger information displays currently exist.

- The park and ride potential has not been fully developed. 
- Dwell time at stops could be reduced with contactless smart-card technology and if bus drivers opened the middle door on the bus (this is not common practice due to a problem with operational management).

Some of the above have added to the difficulties for some QBCs to perform to their full potential.

\section{THE STILLORGAN QBC AS A CASE STUDY}

The Stillorgan QBC is shown in Figure 1. It was implemented in August 1999 with the input of two local authorities, one bus company and the police force. The QBC straddles two local authority areas - Dublin Corporation (CBD) and Dun Laoghaire-Rathdown County Council (south city). The bus company involved was the state bus company for Dublin city - Bus Atha Cliath (BAC).

In terms of transit supply, the route remained unchanged. Service levels were increased from frequencies of 4 per hour to 12 in the peak hours and 8 in the off-peak hours. Station/stop spacing remains unchanged. There is wide variability in the distances between stops. The increase in the number of vehicles to provide the QBC service was cited as having a significantly positive effect although it is not clear how many additional vehicles have been added. (It is hoped to clarify this point shortly). There was no change in fares as a result of the QBC. Fares vary with distance and are priced on the same basis as all other Dublin bus services.

Three variables are examined in the analysis of the Stillorgan QBC - on-board bus passenger counts, car and bus travel times and reliability of the service frequency. Where possible the variable calculations are based on those in the TCQSM (7). As mentioned, earlier the service frequency LOS is A compared with much poorer LOS levels of C/D before implementation.

Accessibility was not measured as suggested in the TCQSM (7) i.e. measuring the pedestrian travel time to a stop from $0.4 \mathrm{~km}$ away. However, all stops are adjacent to pathways with kerbs and some stops are within $300 \mathrm{~m}$ of each other. Almost all junctions on the route are signalised with pedestrian phases available. In some parts of Dublin, particularly in the city centre where there are large pedestrian flows, pedestrian green times are allocated with relatively high frequency. However, on the Stillorgan route where dual-carriageways (two lane in each direction) form a large proportion of the route and speeds are quite high (speed limit $40 \mathrm{~km} / \mathrm{hr}$ but speeds are considerably higher than this), pedestrian green times are allocated but vehicles are given higher priority in the sequencing of green times.

The TCQSM (7) recommends management of service frequency to avoid the situation where full buses pass stops and waiting passengers due to overloading. In the case of the Stillorgan QBC full buses passing waiting passengers is a common occurrence in the morning peak period but passengers are considerably less concerned since introduction of the QBC than before because they know that other buses will come shortly after. There is possibly some scope here to improve this situation using the guidelines suggested in the TCQSM (7).

Other measures include Hours of Service LOS. In the TCQCM (7) this LOS is defined as the number of hours a day that a service operates at least once per hour. The 
Stillorgan QBC has an Hours of Service LOS of B/C of 16.5 hours and operates at a Service Frequency of LOS A during that period.

\section{Passenger Counts}

Inbound and outbound passenger counts by BAC presented in Table 1 and Table 2 demonstrate the impact of the QBC on the Stillorgan route corridor. In Table 1, it can be seen that there is a significant increase of $150 \%$ in passenger numbers during the morning peak period (07.00 - 09.14) after the QBC was implemented. Another large increase of $58 \%$ is noticeable during the shoulder of peak period and mid-morning off-peak period. There is a general increase in demand during the rest of the day but the other significant increase in the period 00.00 - 06.59 of $149 \%$ indicates much increased demand in this period although the base to which the difference is compared is relatively low at 279. It is likely that the increase is due to the early shoulder of the morning peak period.

When looking at the data for outbound passengers in Table 2, there is a significant increase of $144 \%$ during the evening peak period of 16.30 - 18.29. Sizeable increases also exist for other periods throughout the day. The noticeable increase in the peak periods in both morning and evening indicate a significant transport mode shift towards bus after implementation of the QBC.

\section{Travel Times}

The Transit/Auto Travel Time LOS is defined in the TCQSM (7) on the basis of the doorto-door travel time i.e. including walking and waiting time for transit/bus passengers. However, in the following analysis the travel time used is the in-vehicle travel time. Further work will be necessary to complete this analysis in line with that recommended in the TCQSM (7). Having said that, the analysis generated some interesting findings i.e. in congested conditions, the provision of dedicated road space for buses can result in faster travel times compared with cars. This reinforces the comment made in the TCQSM (7) referring to the likelihood of obtaining higher Transit/Auto Travel Time LOS in the peak periods than in the off-peak periods.

Comparisons between average bus and car travel times (in-vehicle time) are presented for inbound traffic for one bus service, the 46A, for different journey start times throughout the day on a $16 \mathrm{~km}$ stretch of the Stillorgan QBC in Figure 2. In the morning and evening peak periods, generally the bus travel times are less than corresponding car travel times. In the morning peak period, bus travel times range from 3 - 24 minutes faster than corresponding car journeys. In the off peak period around midday, car journeys take $2-9$ minutes less than bus but in the evening peak period there is a trend towards quicker bus journey times. In four out of the six trip comparisons in the evening peak, the bus travel time was shorter by $1-6.5$ minutes although one of the other two journeys took 12.7 minutes longer than car. In summary, for inbound travel times, the bus performs favourably compared with car in the peak period but is slower than car in the off peak period. The reason for the difference is likely to be due to the higher congestion levels experienced in car lanes in the peak periods with lower congestion levels in the off peak period influencing car travel times less. 
A similar comparison is performed in Figure 3 for outbound journeys. In the morning peak period, four out of the six journeys are faster by car by $0.25-8$ minutes and the journey times for the other two trips for both modes are almost the same. In the off peak period, three journeys are faster by car by $7-10$ minutes and the other trips have more or less the same travel time by both modes. In the evening peak period, four journeys are faster by bus by between $1-12$ minutes, the travel time for one journey was almost the same for both and one trip was faster by car by 5 minutes. In this case as well as in the case of inbound, it is clear that the benefits of bus usage are more apparent in peak period times where congestion impacts more heavily on car transport. In essence, the dedication of road space to bus transport serves as a substantial disbenefit to car drivers in peak periods.

\section{Reliability of Service Frequency}

A reliability survey was conducted to investigate if the service frequency reliability altered after implementation of the QBC. The results for inbound travel in the morning peak period are shown in Figure 4 where the published timetable arrival time and the actual arrival time are compared for the before and after implementation case. It can be seen that the reliability of the service improves considerably after implementation in the morning peak period. A similar set of results is presented for the evening peak period for outbound travel. In this case, improvement in frequency is not evident to any great degree. Further work is to be done to evaluate reliability more fully.

\section{IMPLICATIONS OF FINDINGS}

The implications of the findings of this paper are significant. A high degree of scepticism existed in Dublin before the QBCs were introduced regarding the potential they would have in attracting car users to bus and their ability to perform to a high LOS. Although there have been mixed findings i.e. some QBCs have out-performed expectations while others show marginal increases in ridership, some issues can be identified as critical from the analysis and from the study in general, in terms of implications of QBC introduction.

The QBC studied above has worked due to the following:

- Dedicated road space is extremely important to enable bus travel times to compete favourably with car travel times

- The QBCs located on roads where road width was not an issue perform much better than QBCs on narrow streets where the provision of both dedicated bus lanes and car lanes are difficult

- The Service Frequency LOS A is another key element in the success of the Stillorgan QBC. The service frequency is high enough that users do not need a timetable. This factor has been highlighted time and time again since introduction of the QBC as having a significant influence in attracting more people to the service. 
- The findings would indicate that the performance and LOS criteria outlined in the TCQSM (1999) are extremely relevant in evaluating the performance of tranit services.

\section{CONCLUSIONS}

The aim of the paper was to review the impact of the implementation of Quality Bus Corridors (QBC) - a term used to describe a bus service which has dedicated road space, higher levels of frequency and some priority - in Dublin. Dublin has chosen to use bus transport as a significant element of its future transportation plans and so its initial experience with QBCs is important particularly in terms of their effectiveness in reducing the transportation supply deficit in Dublin.

The main conclusions of the work are as follows:

1. The introduction of QBCs on some of Dublin's bus routes has made a significant positive impact on bus travel.

2. The enforcement of dedicated road space for bus transport has been the key element in ensuring that QBCs deliver an improved service; more evident in the peak periods when car volumes and associated congestion in car lanes is high. This improved service was demonstrated by comparing bus and car travel times. In the peak periods, bus travel times were less than for car but in off peak periods the reverse was more common.

3. There is an interesting follow-on conclusion from the points raised in conclusion 2. The two key elements which appear to enable the QBCs to be successful is firstly the dedicated road space and increased frequency. Secondly and perhaps more interestingly it appears for the service to compete favourably with car in terms of travel time traffic congestion must be present in the car lanes.

4. There were significant passenger increases, of the order of $150 \%$, on the (city) inbound direction in the morning peak period and corresponding increases in the outbound route in the evening peak period. Increases in passenger numbers were evident throughout the day mostly in the range of $20-50 \%$.

5. Reliability of service frequency was found to increase in the morning peak period on the inbound direction but there was less evidence of improvement in the evening peak period. Further work is necessary to investigate this more fully. 


\section{REFERENCES}

(1) Brady Shipman Martin, Kirk McClure Morton, Fitzpatrick Associates \& Colin Buchanan \& Partners, Strategic Planning Guidelines, Department of the Environment, Dublin, Ireland, 1999.

(2) Dublin Transportation Office, A Platform for Change, Dublin, Ireland. Sept. 2000.

(3) Steer Davies Gleave, Dublin Transportation Initiative Final Report, Department of the Environment, Dublin, Ireland, 1995.

(4) Dublin Transportation Office, Transportation Review and Short-term Action Plan, Dublin Transportation Office, Dublin, Ireland, 1998.

(5) Government of Ireland, National Development Plan (2000 - 2006). Irish Government Publications Office, Dublin, Ireland , 1999.

(6) Scott Wilson, Bus Network Strategy Appraisal Report for the Greater Dublin Area, Dublin Bus (Bus Atha Cliath), Dublin, Ireland, 2000.

(7) TCQSM (1999). Transit Capacity and Quality Service Manual. Kittleson \& Associates. Transit Cooperative Research Program. US.

(8) Bus Atha Cliath, Bus passenger counts for Stillorgan QBC, Dublin, Ireland , 1999.

(9) Dublin Transportation Office, QBC website - http://www.dto.ie/qbc.htm. Accessed on $31^{\text {st }}$ July 2001. 


\section{TABLES AND FIGURES}

\section{TABLES}

Table 1. Weekly inbound passenger counts for before and after implementation of the Stillorgan QBC (8)

Table 2. Weekly outbound passenger counts for before and after implementation of the Stillorgan QBC (8)

\section{FIGURES}

Figure 1. Quality bus corridors routes in Dublin

Figure 2 Inbound bus and car travel times on Stillorgan QBC

Figure 3 Outbound bus and car travel times for Stillorgan QBC

Figure 4 Reliability of service frequency comparison for the morning peak period for before and after implementation of the Stillorgan QBC

Figure 5 Reliability of service frequency comparison in the evening peak period for before and after implementation of the Stillorgan QBC 


\begin{tabular}{|l|l|l|l|l|}
\hline \multicolumn{5}{|l|}{ INBOUND } \\
\hline Time Band & $\mathbf{1 9 9 8}$ (before) & $\mathbf{1 9 9 9}$ (after) & Change & \% Change \\
\hline $\mathbf{0 0 . 0 0}-\mathbf{0 6 . 5 9}$ & 279 & 694 & 415 & 149 \\
\hline $\mathbf{0 7 . 0 0}-\mathbf{0 9 . 1 4}$ & 9962 & 24902 & 14940 & 150 \\
\hline $\mathbf{0 9 . 1 5}-\mathbf{1 1 . 5 9}$ & 7024 & 11101 & 4077 & 58 \\
\hline $\mathbf{1 2 . 0 0}-\mathbf{1 3 . 5 9}$ & 4459 & 6592 & 2133 & 48 \\
\hline $\mathbf{1 4 . 0 0}-\mathbf{1 6 . 2 9}$ & 8473 & 12374 & 3901 & 46 \\
\hline $\mathbf{1 6 . 3 0}-\mathbf{1 8 . 2 9}$ & 5014 & 6918 & 1904 & 38 \\
\hline $\mathbf{1 8 . 3 0}-\mathbf{2 1 . 5 9}$ & 5654 & 7730 & 2076 & 37 \\
\hline $\mathbf{2 2 . 0 0}-\mathbf{2 3 . 5 9}$ & 1593 & 1662 & 69 & 4 \\
\hline Total & 42458 & 71973 & 29515 & 70 \\
\hline
\end{tabular}

Table 1. Weekly inbound passenger counts for before and after implementation of the Stillorgan QBC (8) 


\begin{tabular}{|l|l|l|l|l|}
\hline OUTBOUND & $\mathbf{1 9 9 9}$ (after) & Change & \% Change \\
\hline Time Band & $\mathbf{1 9 9 8}$ (befor) & $\mathbf{1 9 9}$ & 15 \\
\hline $\mathbf{0 0 . 0 0}-\mathbf{0 6 . 5 9}$ & 269 & 310 & 41 & 40 \\
\hline $\mathbf{0 7 . 0 0}-\mathbf{0 9 . 1 4}$ & 6080 & 8493 & 2413 & 32 \\
\hline $\mathbf{0 9 . 1 5}-\mathbf{1 1 . 5 9}$ & 4531 & 5980 & 1449 & 37 \\
\hline $\mathbf{1 2 . 0 0}-\mathbf{1 3 . 5 9}$ & 4303 & 5887 & 1584 & 54 \\
\hline $\mathbf{1 4 . 0 0}-\mathbf{1 6 . 2 9}$ & 9872 & 15168 & 5296 & 144 \\
\hline $\mathbf{1 6 . 3 0}-\mathbf{1 8 . 2 9}$ & 5154 & 12585 & 7431 & 38 \\
\hline $\mathbf{1 8 . 3 0}-\mathbf{2 1 . 5 9}$ & 6498 & 8957 & 2459 & 48 \\
\hline $\mathbf{2 2 . 0 0}-\mathbf{2 3 . 5 9}$ & 1784 & 2636 & 852 & 56 \\
\hline Total & 38491 & 60016 & 21525 & \\
\hline
\end{tabular}

Table 2. Weekly outbound passenger counts for before and after implementation of the Stillorgan QBC (8) 


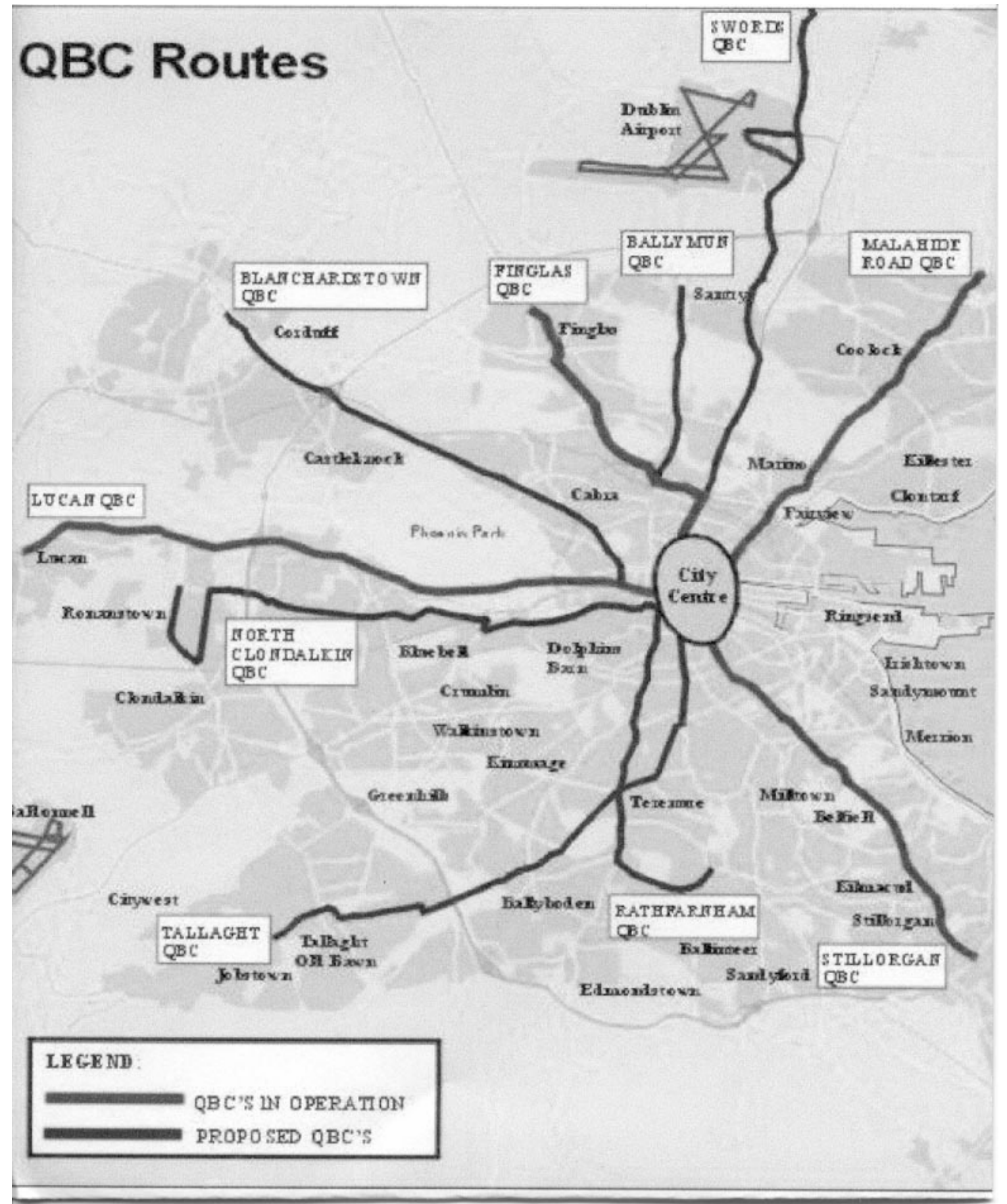

Figure 1. Quality bus corridors routes in Dublin (9) 


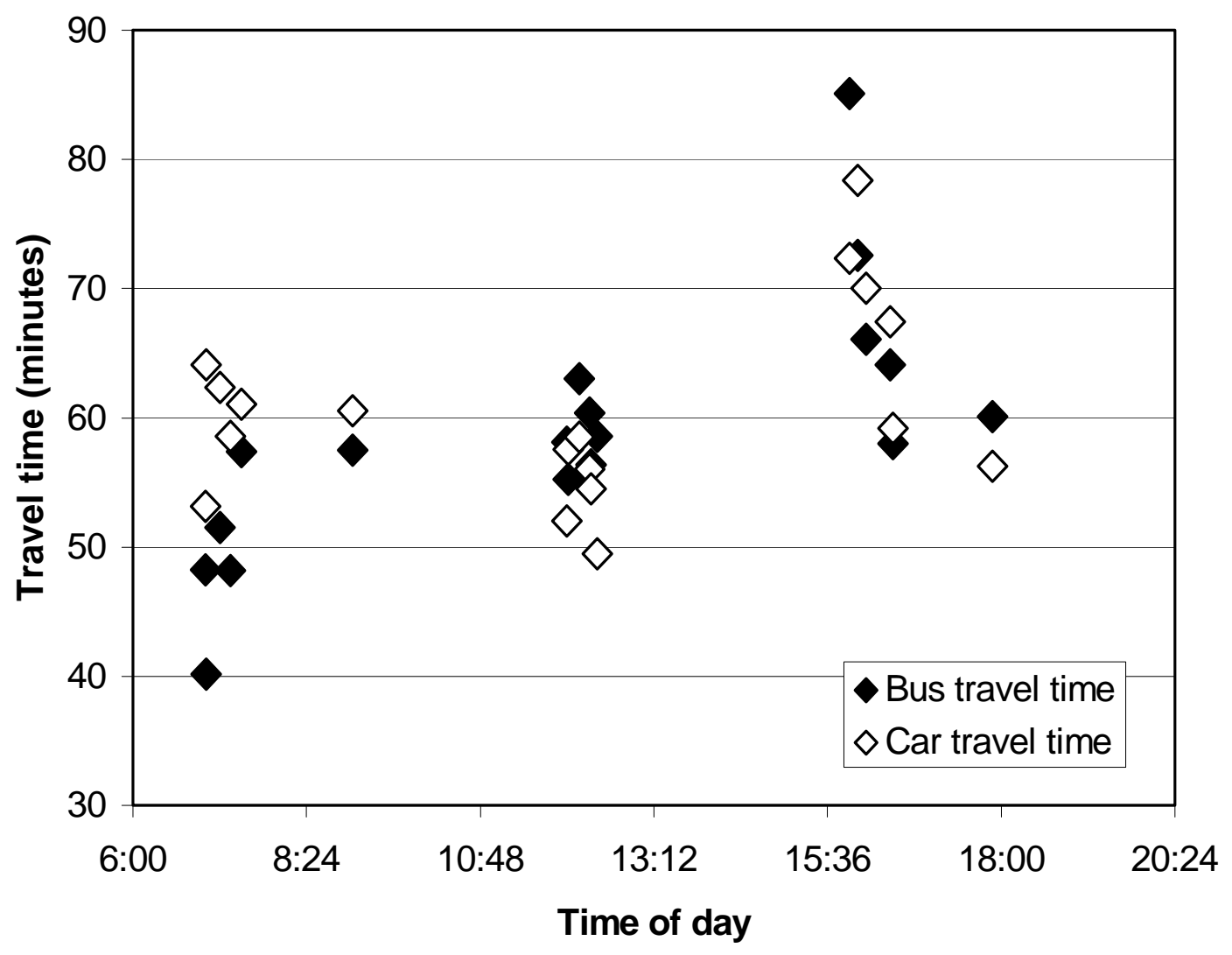

Figure 2 Inbound bus and car travel times on Stillorgan QBC 


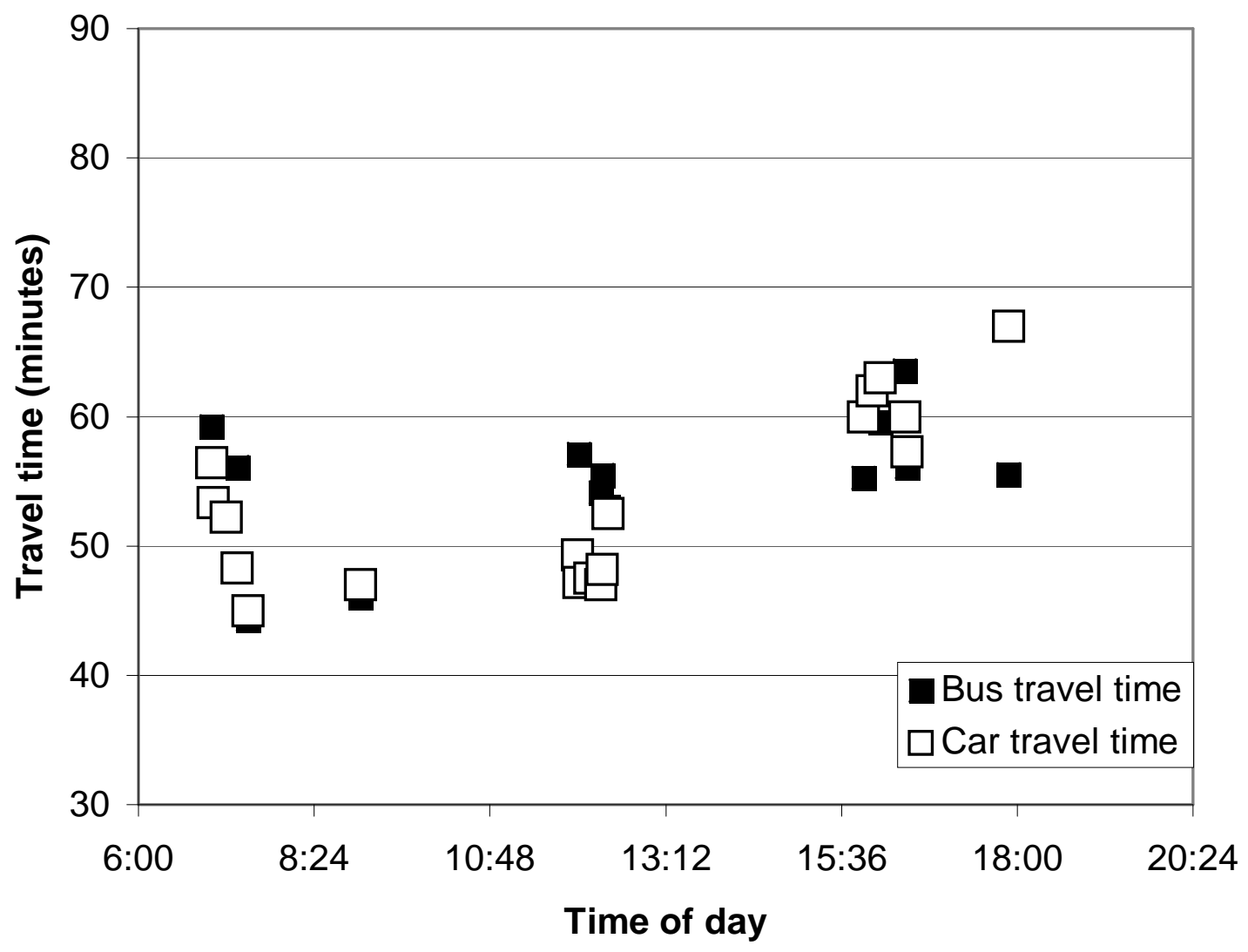

Figure 3 Outbound bus and car travel times for Stillorgan QBC 


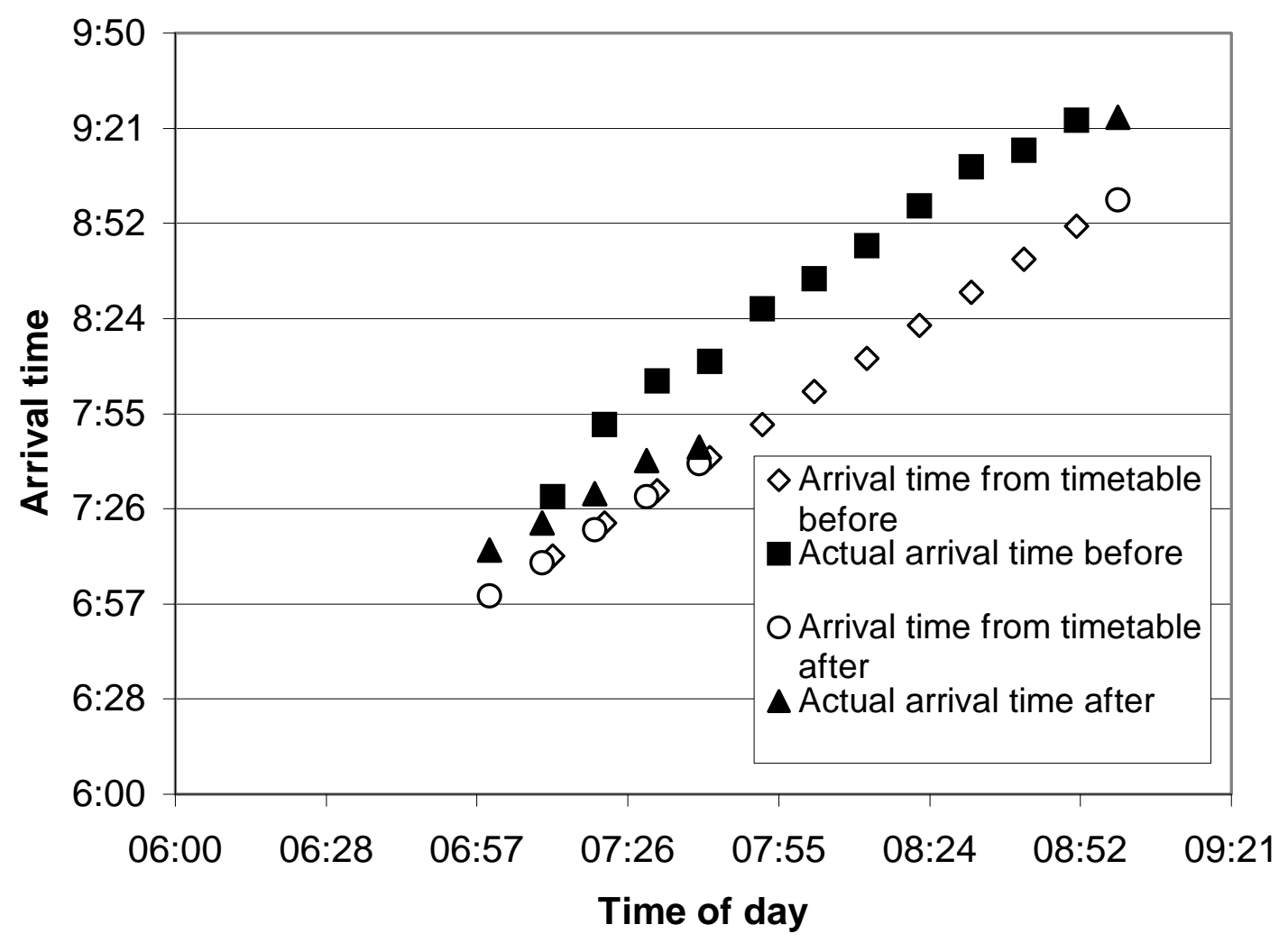

Figure 4 Reliability of service frequency comparison for the morning peak period for before and after implementation of the Stillorgan QBC 


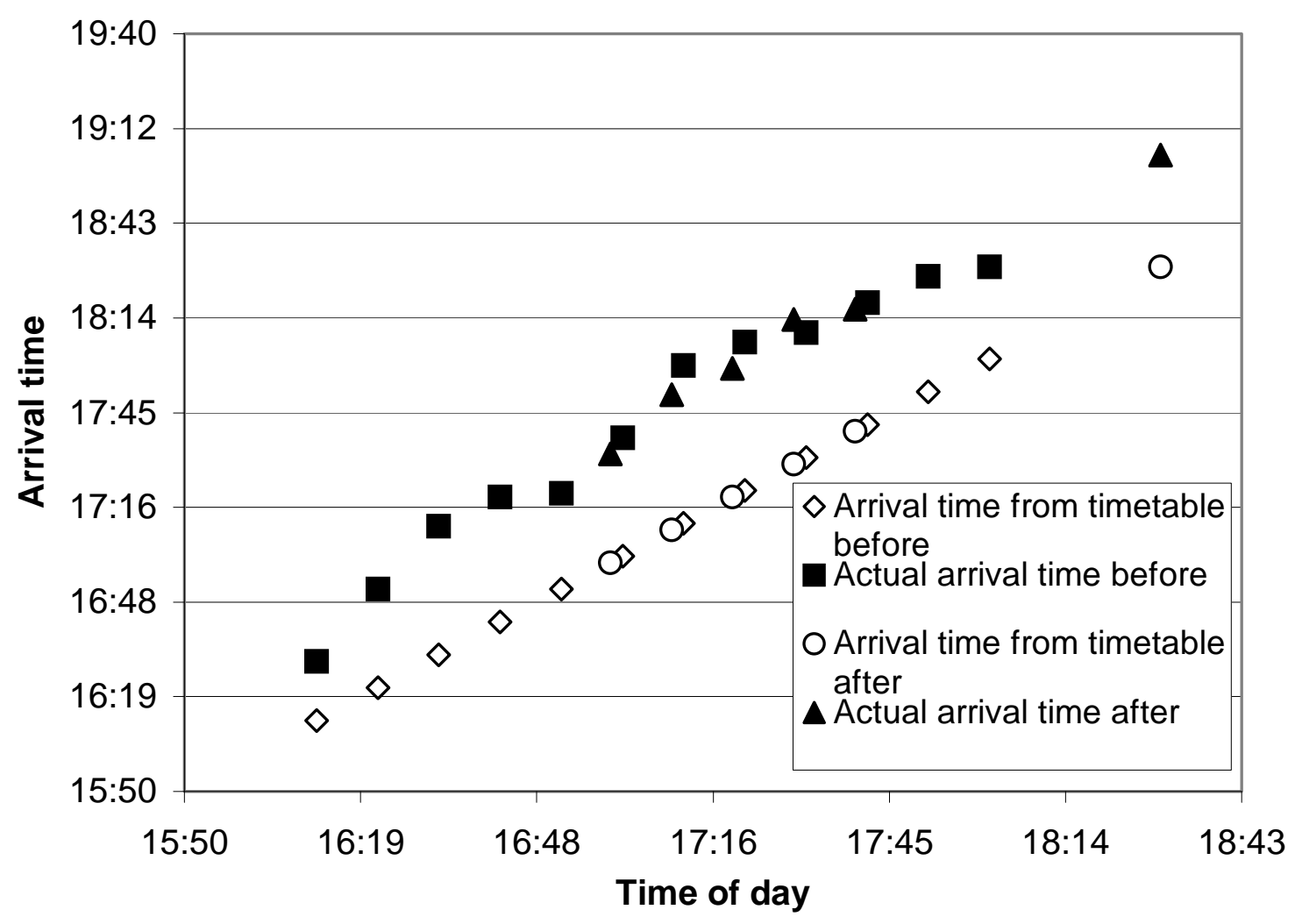

Figure 5 Reliability of service frequency comparison in the evening peak period for before and after implementation of the Stillorgan QBC 